AgnieszKa Flisek

Uniwersytet Warszawski

a.b.flisek@uw.edu.pl

KatARZYna MoszczYŃSKa-Dürst

Uniwersytet Warszawski

k.moszczynska@uw.edu.pl

\title{
ROMANCE DE LA NEGRA RUBIA DE GABRIELA CABEZÓN CÁMARA: ENTRE LA AUTOBIOGRAFÍA TRÁNSFUGA Y EL AUTORRETRATO DE UN SUJETO CÍNICO
}

Fecha de recepción: 01.10 .2020

Fecha de aceptación: 10.11 .2020

Resumen: Romance de la Negra Rubia (2014) de Gabriela Cabezón Cámara es una autobiografía ficcional de Gabi, una paria que con su cara quemada concebida como símbolo de protesta popular consigue llegar a las cumbres del poder. Nuestro propósito es examinar las diferentes modulaciones de la voz narrativa de la novela, una voz que se desliza rápidamente de la compasión o la autocompasión en la burla, el sarcasmo y la parodia para desenmascarar la lucha popular como una performance, la experiencia límite del dolor y la muerte como una instalación y una puesta en escena mediática, la contracultura y la estética transgresora como arte servil a la hegemonía de la mercantilización, el amor como un constructo cultural patriarcal y un producto del "consumo de la utopía romántica”. Observaremos la manera en que este yo, que privilegia la ironía como modalidad expresiva por su radical antifundamentalismo epistemológico y axiológico, se aleja de la autobiografía tránsfuga modélica y construye el autorretrato de un sujeto que asume la máscara cínica para desmontar el espectáculo cínico de la sociedad contemporánea.

Palabras clave: autobiografía tránsfuga, dentro/fuera (mecanismos del poder), cinismo, pasión, parodia

Title: Gabriela Cabezón Cámara’s Romance de la Negra Rubia: between the Transfuge Autobiography and the Self-portrait of a Cynical Subject

\begin{abstract}
Romance de la Negra Rubia (2014) by Gabriela Cabezón Cámara is a fictional autobiography of Gabi, a pariah who with her burned face conceived as a symbol of popular protest manages to reach the heights of power. Our aim is to examine the different modulations of the narrator's voice, which rapidly moves from compassion or self-pity to mockery, sarcasm or parody so as to unmask the popular struggle as a performance, the extreme experience of pain and death as an installation and a mass-media staging, the counterculture and transgressive aesthetics as art enslaved by the hegemony of commodisation, love as a patriarchal cultural construct the product of "consuming the romantic utopia". We will observe how this subjectivity that privileges irony as an expressive modality due to its radical epistemological and axiological antifundamentalism, shifts away from the exemplary transfuge autobiography and creates the self-portrait of a subject that assumes the cynical mask to dismantle the cynical spectacle of contemporary society.
\end{abstract}

Keywords: transfuge autobiography, inside/outside (power mechanisms), cynicism, passion, parody 


\section{1. ¿HACIA UNA AUTOBIOGRAFÍA TRÁNSFUGA DE LA “NEGRA RUBIA"?}

Cuando el yo -el sujeto que habla- intenta inscribirse en el "espacio biográfico" (Arfuch $2002)^{1}$, pronto nota que, como yo precisamente, está involucrado en una serie de co-textos y contextos sociales que exceden sus capacidades narrativas y que nunca son individuales. Ningún yo puede "dar cuenta de sí mismo", insiste Judith Butler (2009), ningún yo es capaz de contar una historia de vida distinta a la historia de sus relaciones sociales determinadas por una serie de normas impuestas e interiorizadas. Nuestras maneras de ver y vivir el mundo siempre se verán afectadas por esas normas socioculturales que no hemos escogido. De modo que, si el sujeto autobiográfico, como todo sujeto, es un constructo social, su relato de vida no lo habrá creado un "yo auténtico", una autoridad cabal que exista fuera o antes del discurso o del proceso de la sujeción.

Ahora bien, este planteamiento no le niega la agencia al sujeto. Al contrario, se trata de una toma de conciencia que nos lleva a reflexionar de manera crítica sobre cómo un yo se produce y reproduce en el discurso (autobiográfico), qué opciones tiene para resistir la imposición de las normas sociales o, al menos, cómo puede renegociarlas:

La norma no produce al sujeto como su efecto necesario, y el sujeto tampoco tiene plena libertad para ignorar la norma que instaura su reflexividad; uno lucha invariablemente con condiciones de su propia vida que podría no haber elegido. Si en esa lucha hay algún acto de agencia o, incluso, de libertad, se da en el contexto de un campo facilitador y limitante de coacciones. Esa agencia ética nunca está del todo determinada ni es radicalmente libre. Su lucha o su dilema principal deben ser producto de un mundo, aun cuando uno, en cierta forma, debe producirse a sí mismo. (Butler 2009: 33)

En esta línea de pensamiento, en La vida narrada: Memoria, subjetividad y política (2018), Leonor Arfuch nos confronta con un tema crucial para la autobiografía al plantear la cuestión del uso estratégico del yo en la creación de vínculos entre las prácticas discursivas y la situación material y corporal del sujeto que las produce y reproduce. Así, dentro de la tendencia más general de cuestionar textos canónicos convertidos en instrumentos del poder, es desmitificada la autobiografía clásica que privilegia al hombre blanco de clases dominantes (Anderson 2011), al tiempo que se hace hincapié en el potencial político del género como un espacio de resistencia al poder y una herramienta de lucha por un mundo más justo. En palabras de Arfuch:

1 Leonor Arfuch acuña el término "espacio biográfico" que designa diversas formas de las escrituras del "yo" o, más bien, distintos usos autobiográficos: memorias, auto/biografías, diarios, autoficciones, ensayos académicos de corte autobiográfico, reality shows, docudramas, entre otros. Según la teórica, el espacio biográfico es un concepto que da cabida a la coexistencia no-conflictiva de expresiones y subjetividades multifacéticas que, pese a todas sus diferencias, poseen rasgos en común y son el resultado de un "giro autobiográfico": "las implicancias de este giro, de esta vuelta obsesiva sobre la minucia de la subjetividad, son considerables" (2002: 247). 
Es bien reconocido el papel preponderante que ha tenido -y sigue teniendo- la autobiografía de mujeres -y, en general, la asunción de la primera persona en relatos de tinte confesional o testimonial- en la configuración del campo epistémico de los diversos feminismos, los estudios de género y de la diferencia sexual, y la redefinición obligada, desde esas perspectivas, de los conceptos de género, identidad, agencia y experiencia. (2013: 95)

Así, la autobiografía se convierte en "el género de los oprimidos", de parias que devienen tránsfugas de distinta índole y que logran articular, a través de las experiencias individuales, las experiencias colectivas, representativas para cuerpos marginados, antes codificados como "no-llorables" (Butler 2006).

Recordemos que, según Martine Leibovici (2011), los discursos autobiográficos creados por tránsfugas para describir su origen paria y su particular posición social de "insideroutsider" son poderosas vías de (auto)conocimiento de los mecanismos de exclusión social. Así, la autobiografía tránsfuga no es sino una reconstrucción narrativa de la experiencia del cruce de un grupo étnico, racial, socio-económico, cultural al otro. Esta experiencia, el estar entre dos mundos distintos, genera en sujetos tránsfugas, según la filósofa francesa, un malestar resultante de una incapacidad de asentamiento mental duradero: "Cette trajectoire ne peut être reconstituée qu'après la traversée, mais alors la période de l'entredeux-rives s'est transmuée en disposition, en une incapacité d'installation mentale durable" (95). En este sentido, dichos discursos del yo nunca se acercan a las fórmulas propias de un simple Bildungsroman emancipatorio, ya que no concluyen con la victoria final de un ego anteriormente marginado, que ha logrado superar no solo las trabas sociales sino también los dilemas y las contradicciones que han marcado su relato. Si bien el/ la autor/a tránsfuga siguió una trayectoria singular que lo separa de sus orígenes parias, la sensación del malestar sigue siendo un elemento constitutivo de su subjetividad:

les autobiographies de transfuges ne se présentent jamais comme des Bildungsromane s'achevant par la conquête enfin acquise du Moi ayant dépassé les errances et les contradictions de la jeunesse. Même si l'auteur a suivi un destin singulier par rapport à ceux de son groupe d'origine, les incertitudes, les dilemmes, le malaise restent constitutifs de son être. (97)

De ahí que las autobiografías de los y las tránsfugas sean siempre personales y políticas, de ahí que siempre estén impregnadas de emociones y pasiones que han marcado su trayectoria: "En tant quécriture de soi, cette compréhension s'effectue grâce à une analyse interprétative des affects ressentis par l'auteur dans certaines situations, vécues la plupart du temps dans l'enfance ou la jeunesse - honte, humiliation, colère, révolte, mais aussi envie, jalousie ou ambition" (94).

En estas prácticas discursivas del yo podría inscribirse la autobiografía ficcional de Gabi, la protagonista de la nouvelle de Cabezón Cámara que nace negra y se vuelve rubia, que de una poeta under se convierte en una bonza, y de ahí en santa, mártir y líder de un grupo marginalizado; que de un amasijo de carne quemada se transforma en una obra de arte viviente exhibida en la Bienal de Venecia, y de ahí en la amante de una extranjera rica quien, además de un sinfín de bienes, le deja en herencia su propia cara; y de ahí 
en una activista política y una gobernadora, y de ahí, finalmente, en una escritora que, en las alturas de su penthouse en Tigre, escribe el relato de su vida.

Este relato bien podría considerarse una autobiografía tránsfuga, y no solo porque los pasajes, desvíos y cruces de género, sexualidad, clase social, marginalidad y poder sean sus leitmotifs o elementos constitutivos. Lo sería también porque, como subraya Nora Domínguez, además de plasmar los "pensamientos, decisiones, imaginaciones [y] deseos" del sujeto hablante, "construye a su alrededor [...] a una comunidad potenciadora y cobijadora que [lo] sostiene, una sociedad con sus sujetos vulnerables" (2018: 41), convirtiéndose de esta manera -al menos potencialmente- en un relato de denuncia y resistencia.

De hecho, Romance de la Negra Rubia se mueve "entre lo singular y lo colectivo" (Domínguez 2018), pero más que una narración doble, a la vez política y personal -como quisiera Leibovici- es una narración desdoblada, escindida en dos relatos. Uno de ellos se inclina hacia lo colectivo y público, el otro hacia lo personal e íntimo. La bisagra que los une, según Alicia Montes, es el motivo de sacrificio o entrega del cuerpo de la mujer (2018: 29) ${ }^{2}$. Podríamos pensar entonces que lo que mueve a la protagonista y lo que marca su escritura autobiográfica es la "pasión del Otro", para citar a Osvaldo Lamborghini (1988: 93), quien no solo es uno de los grandes creadores de la autoficción, sino también quien simboliza la marginalidad en el campo literario argentino. Ahora bien, mientras en el primero de los relatos de Gabi (según el orden de aparición en la nouvelle), el Otro son las minorías, es este "pueblo que falta" (Deleuze 2006: 19) por el que ella habría querido sacrificar su vida y a cuyo encuentro sale su escritura (minorizada); en el segundo, el Otro es el otro del amor, pasión que conduce a Gabi a diluir su ser, a convertirse -literalmente- en la otra, en Elena, y que, a su vez, hace que su escritura autobiográfica se diluya en la retórica -y en los clichés- de los discursos amorosos. Pero vayamos por partes.

\section{PASIÓN POR “EL PUEBLO QUE FALTA”, O CÓMO SER “LA VOZ DE LOS SIN VOZ”}

La nouvelle comienza con la escena de la intervención policial en el edificio tomado por un grupo de aristas okupas ${ }^{3}$. Para defenderlos del desalojo Gabi se quema a lo bonzo. Ciertamente, no puede haber un sacrificio mayor que el de dar la vida por un semejante, un compromiso con la comunidad más auténtico que el que lleva la resistencia contra el poder al extremo de la muerte. La dinámica del sufrimiento, el sacrificio y la liberación, del páthos, la passio

2 De hecho, para Alicia Montes son dos mujeres diferentes las que ofrendan sus cuerpos en cada uno de los relatos: en el primero es la negra Gabi quien "se prende fuego a sí misma para evitar el desalojo de una comunidad marginal"; en el segundo es Elena, la rubia suiza enferma de cáncer que "se enamora de la mujer quemada y le dona su rostro". Sin embargo, en este segundo caso, discrepamos con la autora en llamar este acto "ofrenda, todavía menos «sacrificio", ya que, como ella misma admite, Elena lo hizo "para trascender la muerte y vivir en [Gabi] como creadora de una obra de arte" (2018: 19).

3 Como La Virgen Cabeza (2009), la primera novela de Cabezón Cámara, Romance de la Negra Rubia respira el aire de la actualidad: la de los años 2010 y de la Buenos Aires gobernada por Mauricio Macri (20072015), donde, según observa María Eugenia Goicoechea, crecen "las barreras urbanas, simbólicas y físicas, que fragmentan aún más la ciudad, aumentan los hechos de violencia urbana y securitización, gentrificación y desplazamientos" (2018: 144). 
y el pésaj, que se cruzan en este acto de autoinmolación como los alfabetos en el letrero colocado encima de la corona de espinas, en una tragedia griega hubiera estado orientada a despertar emociones intensas que, a su vez, hubieran llevado a una experiencia particular de comprensión. El coro de Agamenón de Esquilo la resume de manera lapidaria en su parodos: pathei matos, la sabiduría mediante el sufrimiento (cf. Szczurowski 2018: 368-372).

Pero Romance de la Negra Rubia viene a demostrarnos que "est[aba] equivocado el coro y el corifeo" (Cabezón Cámara 2014: 29): en el sufrimiento no se incuba otro saber que no sea un saber instrumental que hace uso del sufrimiento en pos de la ganancia. De ahí que la historia de la sobreviviente del martirio quede despojada de cualquier amago del pathos. La narradora se niega a apelar a emociones fuertes, optando por una mirada distanciada y mordaz con la que recorre el universo social y cultural que la rodea, mirada que también dirige a sí misma.

Ahora bien, el relato de Gabi, que se inició como un blog ("Yo empecé a escribir un blog donde puse parte de esto que estoy reescribiendo ahora", 37), una de las más democráticas, pero, a la vez, la más exhibicionista de las formas de expresión de reflexiones y experiencias personales, como toda escritura confesional se rige -coincidimos en este punto con Alberto Giordano- por una "improbable voluntad de querer-ser-sincer[a]-consigo-mism[a]" (Giordano 2013: 4). Improbable, porque, según explica Giordano en su ensayo "Autoficción: literatura y vida", no es el principio de sinceridad sino el de falsificación el que gobierna los textos autobiográficos en los que siempre subyace "el deseo de alcanzar un grado de firmeza y claridad que la existencia no consiente" (4). De modo que "se escriben [...] las confesiones de alguien más notable, más puro, más sucio, más vivo, más sensible, e incluso más yo que lo permitido, pues el yo tiene grados" (Valéry 1956: 91, apud Giordano 2013: 4). Giordano trae a colación esta observación de Paul Valéry para señalar la distancia que separa al sujeto de la enunciación confesional de la subjetividad supuestamente sincera y que convierte toda confesión en una autofiguración. Es importante en este sentido remarcar la insistencia de la narradora de Romance de la Negra Rubia en resguardarse de idealizaciones, siendo este esfuerzo de desidealizarse, según veremos, la base de su autofiguración como sujeto cínico.

De hecho, Gabi se empeña en restarle cualquier heroísmo a lo que repetidas veces llama, visiblemente regodeándose en esta referencia cultural, "[su] propio asado" (Cabezón Cámara 2014: 27). Pues, si bien no se muestra como una pequeña burguesa titubeante, zarandeada, que necesita saber antes de actuar y que, de esta manera, nunca corre el riesgo de comprometerse, tampoco crea la imagen de sí como una arrojada que lleva, en ofrenda, al altar del bien común, el bien mayor: la vida misma. ¿Qué fue entonces lo que la movió al sacrificio? ¿Las devociones de la ambiciosa que quiso realizar el sueño de la infancia de ser una desaparecida, para "eternizarse en el heroísmo del poster" (Montes 2018: 32), un heroísmo vuelto pura imagen como el del Che Guevara, cuya efigie "circula $[. .$.$] en banderas de tribuna o en remeras, en pintadas callejeras o en cal-$ comanías ubicuas [... porque] pag[ó] el precio de su previa despolitización y su previa desideologización" (Kohan 2014: 200, cf. también Žižek 2011a: 38-39)? Ni eso. Ni el amor a la gloria ni el desprendimiento del interés personal a favor de la felicidad de los otros ${ }^{4}$.

4 Jean Jacques Rousseau (s.f., en línea) considera en su Discours sur la vertu des héros (1751) que ambas son virtudes imprescindibles para los héroes. 
Lo cierto es que detrás de este supuesto martirio no hubo un esfuerzo consciente que se emparentase con una voluntad de abnegación, tan solo un mix prolongado de cocaína y whisky; exceso que trastornó a la protagonista a tal punto que al encontrar los bidones de querosén se los vertió encima y se prendió fuego, aunque, como reconoce después, "hi[zo] todo al revés. Debería haber incendiado a canas y judiciales en vez de volver[se] bonza” (Cabezón Cámara 2014: 25).

Difícil considerar este martirio impensado -más aún, inconsciente- un acto heroico en servicio de la comunidad. También porque no existía en Gabi ningún sentimiento de pertenencia: no formaba parte de la "comunidad arty", ni siquiera la conocía. Como no tarda en explicarnos, apenas era una invitada a la fiesta a la que fue, seducida por la perspectiva de "una roca de merca" y de "seis botellas de whisky" (21). Fueron ellos, los comuneros los que, "con certeros reflejos en segundos" (15), la convirtieron en miembro de la comuna, más aun, en su santa: "se hicieron míos y me hicieron suya los míos y se enardecieron más cuando alguno prendió la tele y se vieron en vivo y a los gritos y con buen criterio de rating" (15).

En lo que sigue y a lo largo de todo su relato, la protagonista nunca se refiere a la "comunidad arty", y a todo el movimiento social de okupas que su martirio originó, de otra forma que "los míos": "entre los míos hubo cuatro caídos" (16), "aquellos de los míos que no estaban presos" (16), "el más frágil de los míos" (16), "el más pequeño de los míos" (17). Sin embargo, no dejamos de percibir su distanciamiento, su ajenidad. En algún momento Gabi reconoce: "Es bastante heterogénea la primera del plural, los nuestros no son nosotros y eso hay que tenerlo claro" (73). La pequeña diferencia morfológica entre el pronombre personal y el pronombre posesivo resulta en un abismo que separa a la comunidad de individuos que -retomando los principios kantianos- son fines en sí, de aquellos que no son sino medios para que los otros puedan conseguir sus fines.

Y así como fue subrayada la exterioridad de Gabi respecto a la comunidad de los excluidos al principio del relato, así también al final queda remarcado su posicionamiento en un afuera. Una vez perdida la fe en el proyecto social utópico, Gabi renuncia a su compromiso político, se aleja, se retira, se va a vivir en un apartamento de mil metros en el piso vigésimo con vista al Río de la Plata, donde se dedica a escribir la historia de su vida. En este sentido no es gratuito el énfasis que, en uno de los numerosos pasajes autorreflexivos de esta nouvelle, la narradora pone en la cuestión de la perspectiva: "cualquier perspectiva es un lugar conseguido, yo no creo que haya lugar totalmente regalado: se llega a la perspectiva, lo que organiza el relato, y si se puede contar es que algo de bueno habrá ahí donde estás parado" (29). En su caso, la escena de la enunciación está autofigurada en términos de la escritura del relato del yo que se narra desde un lugar retirado, luego de haber transitado un periplo. De este modo indica una exterioridad y una distancia con respecto a los hechos que se narran, así como con respecto a los orígenes parias de la protagonista y, de paso, a cualquier compromiso sociopolítico. En tal orden de cosas, si en lugar de ubicarse en un "adentro-afuera", como quisiera Leibovici, la voz narrativa se posiciona solo en un afuera, su relato necesariamente tiene que convertirse en una parodia de la nueva autobiografía en cuanto que el género de los oprimidos.

Ahora bien, como en la mayoría de los textos paródicos, también en Romance de la Negra Rubia esta perspectiva exterior se construye y se sostiene sobre la ironía que tiñe todo 
el discurso, un discurso pronunciado en un tono entre burlesco y sarcástico que no se corresponde con las situaciones dramáticas que había afrontado la protagonista. Queremos decir con esto que no se puede considerar la ironía en esta nouvelle simplemente como un tropo retórico de naturaleza semántica antifrástica que aparece puntualmente, en palabras o frases aisladas, para cumplir con su función pragmática evaluativa, como la define Linda Hutcheon (2000: 52-53). La ironía impregna el texto de Cabezón Cámara en su totalidad, se extiende del tropo a la narración (cf. de Man 1991: 232-233); marcando un permanente distanciamiento entre la enunciadora y el enunciado, entre el yo autobiográfico y el yo empírico y su mundo histórico; subrayando, como quisiera Richard Rorty (1991), el radical antiidealismo epistemológico y axiológico de la narradora.

Precisamente, a través de la ironía, esa ironía que supera la seriedad, lo sublime y el pathos, la pasión del otro e incluso la autocompasión mutan en un cinismo juguetón y desafectado. Un cinismo que debemos entender acá con Peter Sloterdijk como un estado de conciencia postnaïf (2007: 37), una capacidad de ver las contradicciones sociales, pero también, a la manera de André Glucksmann (1982), como una voluntad, a partir de esta constatación de la realidad, de controlarlo todo.

Gabi, en cuanto sujeto en relación con su comunidad política, es una de estas "falsas conciencias ilustradas" que, como escribe el filósofo alemán, se dan cuenta de la distancia que separa las máscaras ideológicas de la realidad social. De hecho, es perfectamente consciente de lo que se esconde tras el traje tejido con falsos gestos de compasión de los periodistas, tras las demostraciones de empatía de los punteros del Pejota (Partido Justicialista) o tras la pantomima de la solidaridad de los jueces. Y, sin embargo, ella también lleva la máscara, porque se rinde al orden de las cosas, porque ha perdido toda ilusión y ha destruido la posibilidad de volver a creer.

¿En qué no cree la narradora? Antes que nada en el sentido de su propio sacrificio que no resulta ser sino un botín, un barril sin fondo para saciar diferentes ambiciones e intereses: "Me usaba bastante el juez y quiso usarme el Pejota para sumarme a la masa, nunca yerta ni acabada, de su mayor capital: el plantel de muertos vivos" (Cabezón Cámara 2014: 37). Gabi, la "negra sombra, una media muerta, con medio cuerpo ascendido hasta el reino celestial" (74), comparte en este sentido el destino de los desaparecidos durante la última dictadura militar en Argentina que brindaron el capital simbólico al poder actual, en este caso al Partido Justicialista: su "asado [...] rindió un poco más que una indigestión pesada" (74).

Sin embargo, la mirada del yo reflexivo no solo abarca la experiencia particular del yo empírico en una coyuntura determinada ${ }^{5}$, también la proyecta sobre la historia universal, ofreciendo una lectura general del sacrificio y de la ganancia que otorga una muerte,

\footnotetext{
5 En "Genealogía del sacrificio: cuerpo y memoria en Romance de la Negra Rubia de Gabriela Cabezón Cámara”, Alicia Montes se encarga de reconstruir detalladamente el contexto político y social y de descifrar muchos sobreentendidos de la actualidad y la historia argentina. Por ejemplo, el "Pejota", que aparece en el fragmento citado más arriba, queda identificado en su ensayo no solo como representante del justicialismo kirchnerista, que -de acuerdo al discurso de derechas, que la narradora repite irónicamente-convirtió el setentismo y la memoria de los desaparecidos en un gran capital político de su poder, sino también como alusión a la Juventud Peronista (mediante la inversión de siglas), "una de las fuerzas más afectadas por la desaparición forzosa durante la dictadura" (2018: 33).
} 
autoinfligida o dispuesta por un poder. Pues, así como el martirio de Gabi origina el gran movimiento social, un movimiento de resistencia -y de un violento contrataque (no se trata de engañar a nadie) - de los sectores económicamente desfavorecidos ante la avidez del sector inmobiliario y la gentrificación de las ciudades, así el sacrificio siempre ha sido el origen, el núcleo fundante de cualquier forma cultural, de cualquier sociedad. ¿O es que acaso Agamenón, reflexiona la narradora, al sacrificar a Ifigenia, aparte de ganarse la bendición de los dioses, no instituyó "el derecho del señor a matar a sus mujeres" (71), originando de esta manera la violencia de género, intrínseca de toda cultura patriarcal? ¿O es que Caín, el agricultor, al matar a su hermano, el pastor, no "inició la tradición de familia y propiedad" (71) y, sobre todo, no echó semilla al sistema de agricultura intensiva, fundamental para el desarrollo de la civilización occidental? ¿ $\mathrm{O}$ es que el holocausto de seis millones de judíos, producto de la "fábrica del nazismo" (72), no produjo a su vez el estado de Israel?

De estas lecturas de los "sacrificios fundantes" - paródicas, sacrílegas o, al menos, políticamente muy incorrectas- surge una clara idea del beneficio que rinde la víctima sacrificial a su comunidad. Pero a diferencia de todas aquellas víctimas ofrendadas a un determinado poder, deidad o idealidad, Gabi sobrevive el martirio y convierte su condición de víctima, su cuerpo hecho un pedazo de carbón, en capital rentable: un capital simbólico, político y económico.

Pues, si los antiguos quínicos exponían su cuerpo activo, desvergonzado y estremecido por el deseo para retar al logos político, ella, cínicamente, usa su cuerpo abyecto, deforme y monstruoso para negociar con el poder. Y si creíamos, como Walter Benjamin, en un "a priori del dolor", es decir en la posibilidad de la crítica, "en la medida en que el dolor nos diga qué es verdadero y qué es falso" (apud Sloterdijk 2007: 23-24), Gabi reduce su cuerpo dolorido a un mero valor de cambio cuando nace en ella el deseo de poder. "Me afilé, me concentré, me adelgacé hasta los huesos" (Cabezón Cámara 2014: 35), relata la narradora, y este despojarse de la carne coincide con el crecimiento de una pija metafórica, de una "tremenda envergadura envidia de mucho macho" (36). La protagonista sacrifica su cuerpo sacrificado y asume la condición masculina del cuerpo activo y destinado a la esfera pública para "hacer el bien" (35): organizar a los comuneros, conectarlos con las "organizaciones populares, centros de estudiantes, punteros políticos, [...] diversos grupos de artistas más o menos insurgentes o emergentes" (19), negociar viviendas y beneficios para todos. Esto es lo que dice haber creído en aquel entonces.

En el presente de la narración, sin embargo, el "yo reflexivo" reconoce que este falo no era sino el significante del deseo del poder, de esa "actividad voluptuosa", como diría Georges Bataille, "excesiva por esencia, [...] que se desea por sí misma, y a través del deseo del exceso que la constituye" (2010: 174). "Vivía al palo todo el día -confiesa la narradora[...] giró toda mi vida en torno a esa calentura, la de tener más poder, la de poder ayudar y poder mandar al muere, la de poner en las listas y la de sacar de juego. [...] ya no hubo más para mí que el deseo de tener más" (Cabezón Cámara 2014: 35).

Pero cuando Gabi parecía dejarse arrastrar para siempre por esa ola infinita del deseo, por esa pasión que los griegos llamaban la hybris, la desmesura del poder, que la llevó a "[cojerse] a medio país" (36), se produce un nuevo punto de fuga. La llevan como objeto de arte a la Bienal de Venecia. Su cuerpo carbonizado es el centro de una instalación que 
homenajea a los héroes sacrificados desde Jesucristo y los mártires de la Iglesia, pasando por los indígenas de América y otros pueblos colonizados, los soldados-carne de cañón de todas las guerras, hasta los desaparecidos por Videla \& co.

Así es como Gabi se convierte en un producto cultural. Su corporalidad herida se inscribe en un espacio diseminado y fragmentado, un espacio hecho de elementos divergentes y entrópicos del capitalismo avanzado. No es en este sentido una excepción, si bien es la única que de un arte vivo, un arte ready-made, una performance realizada en un ambiente cotidiano, pasa a ser un objeto, primero exhibido en el museo y luego adquirido, con toda la instalación, por una coleccionista privada.

Pero lo cierto es que en esta nouvelle ninguna experiencia límite del dolor y la muerte, de hecho, ninguna experiencia -tampoco, la del amor, como veremos más adelante-es si no está representada, más aun, si no está convertida en una imagen, en una instalación o en una puesta en escena mediática. La comprensión o autocomprensión no se alcanza mediante el sufrimiento, como creían los antiguos griegos. Tampoco en un movimiento reflexivo y hermenéutico del sujeto que sale y retorna a sí mismo, en un autoentendimiento mediado por signos, símbolos y textos, como querría Paul Ricœur (2001: 31). En nuestra sociedad de la imagen, según profetizó en los años 60 Guy Debord (2008), la autocomprensión pasa necesariamente por la espectacularización. De hecho, la historia del desalojo, la de su autoinmolación y de su santificación Gabi la conoce exclusivamente de forma mediatizada: "Yo estuve ahí, pero todo esto me lo contaron después" (Cabezón Cámara 2014: 14). Y lo que le contaron fue lo que había transmitido la televisión, lo que había cubierto la prensa gráfica, lo que los testigos habían subido a las redes sociales, lo que habían registrado en sus teléfonos y sus tabletas.

A la mediatización, mejor dicho a la espectacularización de la experiencia, coadyuvan las malas prácticas de los periodistas: "Llegaron por el fuego, bonza, antorcha humana, titulaban calientes, hinchados de placer, casi chamuscados también ellos" (15). Lo cierto es que la narradora nunca naturaliza la morbosidad de estos medios "carroñeros" y "caranchos" que, como diría Ryszard Kapuściński (1996), en lugar de buscar el sentido de los trágicos acontecimientos, buscan donde conectar la cámara para mostrar de cerca, obscenamente, el sufrimiento y la muerte, y disfrutar, de modo vicario, del dolor ajeno. Tampoco, sin embargo, se priva Gabi del placer de ironizar sobre los que no creen ser si no están al menos treinta segundos en un programa de televisión, el único lugar donde parecen sentirse socialmente reconocidos (Pardo 2008, en línea), y que convierten su dolor por la pérdida de un ser querido en una función para extraños.

He aquí uno de los principales mecanismos de este espectáculo cínico en el que ha devenido la sociedad contemporánea descrita en la nouvelle de Cabezón Cámara: negar a los valores existenciales (el amor, la muerte, el sufrimiento) su carácter de tabú ( $c f$. Środa 1997: 36). El dolor y la desesperación se convierten así en una mercancía que se puede exponer de forma atractiva para el goce de los espectadores. Por ello, la narradora no deja de desenmascarar tampoco a los artistas alternativos, tan fieles a su vocación de "hacer [...] de su vida puro arte" (Cabezón Cámara 2014: 20), que en segundos transforman su campamento de desalojados en una instalación, aunque tampoco tardan mucho para poner sus estéticas transgresoras al servicio de la hegemonía de la mercantilización. 
Igualmente, la narradora no deja de poner de manifiesto la impostura del Estado (que de hecho aparece como negociador, corrupto, evidente), ni de sus secuaces -los policías que llevan a cabo el desalojo- partícipes del teatro de la masculinidad con su "coreografía viril", con su pelo atado bien tirante, "porque ha de tener algo de marcial lo tirante", pero maquillados "con base y rímel y sombra celeste sobre los ojos marrones" (12).

¿Por qué Gabi insiste en mostrarnos la sociedad como un gran espectáculo cínico-fársico? ¿Por qué teatraliza a los sujetos como actores que no cesan de ejecutar sus payasadas, o, al menos, de convertir sus acciones en actuaciones? ¿Por qué su narración está marcada por una constante estilización y estetización de la cotidianidad? Pensemos, en este sentido, en la imagen de los pantalones y los borceguíes de los milicos que abre la novela, mejor dicho en esta miríada de imágenes fragmentadas, inconexas en las que la línea, el color, la textura, el volumen, la luminosidad retienen nuestra atención, provocando, obviamente, el diferimiento del sentido y una rarificación de la referencia social. Si la narradora, una y otra vez, pone de manifiesto que la historia de su martirio, santificación y empoderamiento es un producto mediatizado (mediatizado doblemente: por los medios de comunicación y bajo su propia mirada artística), si relativiza de este modo el valor testimonial de su relato es porque en su perspectiva no cabe ningún fundamento no defraudante, ningún valor que proteja de la desilusión, ninguna posición de salvaguarda. El desmoronamiento del mesianismo político, la ausencia de fe en la "aspirina metafísica colectiva" de la acción social (Lorca 2014: 103), la cual constituye el eje de la autobiografía política de Gabi, conduce irremediablemente a una general falta de sentido.

\section{AMOR-PASIÓN O "POSTALES CON FISURAS"}

Podríamos suponer, de acuerdo con las premisas de Beck y Beck-Gernsheim (2001), que en esta parte de la autobiografía ficcional la narradora, confrontada con la derrota de los proyectos utópicos en el ámbito público, codificaría el amor como factor salvador del cinismo generalizado. La pasión por el otro, el amor-salvación -con claras connotaciones religiosas-, podría convertirse de este modo en lugar de culto que se vincularía al "proyecto reflejo del yo" (Giddens 2004) y otorgaría sentido y arraigo a la vida. La mitificación del amor y de la pasión por el otro funcionarían entonces como respuesta al ensimismamiento y al vacío ideológico experimentados por las falsas consciencias ilustradas: "Si no hay Dios, ni cura, ni clase, ni vecino, entonces queda por lo menos el Tú. Y la magnitud del tú es el vacío invertido que reina en todo lo demás" (Beck y Beck-Gernsheim 2001: 57). En este sentido, la mitificación del amor podría surgir como una consecuencia de la desmitificación de las visiones políticas y utópicas, y también como resultado directo de la equiparación de la felicidad -y de la expresión máxima de la identidad-con la esfera privada y la experiencia amorosa. Sin embargo, la historia de amor de Gabi y Elena, que parte del archiconocido esquema del amor a primera vista y que concluye con la encarnación del mito platónico de la media-naranja, se convierte en parodia de prácticas discursivas amorosas de distinta índole; parodia teñida por supuesto de ironía distanciadora, pero también de humor y de mucha literatura. A continuación, nos acercaremos 
a las maneras por las cuales el texto parodia y rearticula mitos, conceptos, géneros y procedimientos literarios del ámbito amoroso.

Según sus propias palabras, Gabi “[se] enamor[ó] [de Elena] en cuanto la vi[o]” (Cabezón Cámara 2014: 49). En varios fragmentos de su narración insiste en la importancia del acto de ver-(re)conocer y subraya que "primero se [le] calentaron los ojos" (49), que "no pud[o] dejar de mirarla" (49) para después confesar reiteradamente: "La miré, la miré, la miré con estos ojos oscuros que sigo teniendo [...] La miré" (49). Ahora bien, ¿̇a qué se debe esta insistencia en el amor a primera vista, en la importancia de la mirada? ¿Cómo la propia narradora interpreta dicho fenómeno? "Me pasó -explica cínicamente- lo que a tanto negro: me gustó por alta, por rubia, por musculosa, por llevar la ropa de lino con elegancia" (48). Con ello, llegamos a la primera desmitificación del discurso amoroso. Recurriendo al humor, Gabi nos confronta con una paradoja, pues si el amor romántico se opone tanto a la praxis feudal de los matrimonios arreglados como a la creciente lógica capitalista, ¿cómo es que a ella le atraen tanto los rasgos europeos y la elegancia, claras señas del bienestar en el imaginario social? La paradoja ya ha sido resuelta por Pierre Bourdieu en La distinción (1988). Según el sociólogo francés, la atracción por las personas, lugares y productos simbólicos está culturalmente determinada y forma parte de los esquemas cognitivo-emocionales semi-conscientes que se van adquiriendo conforme vamos socializándonos y que nos hacen sentir atracción por las personas y las cosas que "nos convienen" (238-241). En términos de Sara Ahmed, diríamos que dichos esquemas generan de manera performativa una atracción basada en "la promesa de la felicidad" que "nos dirige hacia ciertos objetos, en la medida en que se los considera necesarios para alcanzar la buena vida" (2019: 196). En este sentido, el sueño de la buena vida y de la felicidad que promete Elena se representa en la novela, como quiere Ahmed, "por medio de la proximidad a ciertos objetos" (196). Sin lugar a duda, el texto parodia el repertorio afectivo de la felicidad y del amor romántico vividos en el seno de las sociedades consumistas del capitalismo tardío, cuando Gabi, al enamorarse de Elena, se enamora de la promesa de "un determinado tipo de vida, una vida que tiene y hace ciertas cosas" (196).

La "promesa de la felicidad" no es en este caso ni efímera ni vacía. La primera fase de su relación la constituyen los "meses venecianos" a los que Gabi llama "los de las postales por razones obvias" (Cabezón Cámara 2014: 52), aconsejándole a su público lector el siguiente modo de actuar: "Si a alguien se le escapan [estas razones], googlee Venecia y mire las fotos, agréguele romance tropical con precipitación cordial y genital ultrafrecuente, billetera sin fondo, el más infalible de los abrecaminos, el más certero removedor de todo obstáculo" (52). De hecho, el lujo y la distinción no acabaron con los primeros meses de las postales: las protagonistas continuarán su idilio "en Ginebra en Buenos Aires en Tokio en Pekín y en Estambul" (57), porque "quería darle mundo su princesa" (57), su princesa azul: en estos escenarios cosmopolitas triunfa la distinción y... el romance.

Con ello, hemos llegado al siguiente acto de rearticulación desmitificadora. Como sabemos, Cenicienta es el paradigma de "la promesa de la felicidad" descrita arriba, paradigma que no solo subraya las dimensiones de clase y de género, sino que también las interrelaciona: de acuerdo con las reglas de "dominación masculina" (Bourdieu 2000), en la gran mayoría de los cuentos tradicionales, es a las mujeres pobres a las que los príncipes azules pueden salvar y hacer felices. Estas narraciones no contemplan la existencia 
de constelaciones no-heteronormativas ni de relaciones de pareja en las que sea la mujer quien disfrute de una elevada posición social y ofrezca la salvación (económica) a un hombre más pobre y más joven que ella. En este sentido, Cabezón Cámara, reescribe los roles de género, ya que es Elena, y no un hombre, quien le promete a Gabi la felicidad y una mejor vida. Con su relato, la autora argentina nos ofrece una versión queer de Cenicienta en un mundo globalizado y regido por la lógica consumista.

Dicho esto, volvamos al relato sobre el primer encuentro. Inmediatamente después de parodiar el supuesto carácter anti-materialista y exclusivamente heteronormativo del amor, preconizado por los románticos, la narradora evoca las imágenes, las bandas sonoras, y, ante todo, las estrategias de "dilación" (Rincón 2006: 44) propias de las telenovelas. Nos enteramos de que Elena le gustó tanto que "se [le] armó de atardecer en el mar con poema rosa y con música de fondo [...] con una música de esas que ponen en las comedias románticas cuando lo que se va a precipitar es un intercambio de fluidos cuya inminencia seguramente se venía sosteniendo o más bien inflando capítulos y capítulos como un globo cada vez más lleno de flujos con ganas de estallar mezclados" (Cabezón Cámara 2014: 48). Recordemos que uno de los rasgos primordiales de la estructura telenovelesca/de la comedia romántica consiste justo en la mencionada fórmula de "dilación". Estos géneros populares suelen aplazar ad infinitum el enlace amoroso (siempre previsible) para generar de este modo una serie de expectativas y deseo entre el público espectador, ansioso de ver el primer beso (o el primer encuentro erótico) de la pareja protagónica.

Asimismo, la relación directa que se establece en el texto entre el "consumo de la utopía romántica" y la industria cinematográfica no es un factor casual. Como advierte Eva Illouz, desde finales de los años veinte del siglo pasado el amor se convierte en el motivo predilecto del cine y de manera paralela deviene en la herramienta más eficaz y poderosa en el ámbito publicitario. La imagen de los enamorados glorifica y promueve la institución del "matrimonio por amor", pero al mismo tiempo promociona y vende toda una serie de productos asociados al estilo de vida burgués. Se trata ante todo de los productos que deben "expresar el yo", o sea, definir nuestra identidad, mediante el ocio, la moda y la belleza (cf. 2009: 65).

El relato sobre el primer encuentro nos trae a continuación la descripción de Elena, basada en el concepto barroco del amor como una fuerza contradictoria, capaz a su vez de superar toda contradicción. Así, Gabi reescribe a Quevedo, para quien el amor no es sino "hielo abrasador" o "fuego helado", para devolvernos el reflejo oblicuo de Elena, codificada como mujer "ligera y fuerte" (Cabezón Cámara 2014: 48), que podría ser "un tanque ultraliviano" (48) o "un tigre sin hambre" (48), "una Napoleona de vacaciones en Cancún" (48), o "Walt Disney navegando hacia un glaciar" (48). Así, la descripción se alimenta, cada vez más, del campo semántico militar, para desembocar en la imagen de "un misil que atraviesa la atmósfera certero pero apenas arañándola como si fuera un barquito y no un arma de destrucción masiva" (49). De esta manera lúdica, el amor y la guerra se convierten en uno, mientras que el artificio de las concepciones barrocas se hace cada vez más patente.

El primer encuentro culmina con una compra: Elena "se instaló en la instalación al lado mío y me dijo que la compraba" (50), una cena lujosa "con cinco botellas de vino carísimo" (50) y un sorprendente encuentro erótico (sorprendente teniendo en cuenta 
la aludida estrategia de dilación, por un lado, y la herida corporalidad de Gabi, por otro). Curiosamente, la mítica escena del primer beso está ligada a una broma sobre los ideales de la revolución cubana, mejor dicho sobre el ideario de la pureza, la integridad moral y la austeridad del "hombre nuevo": cuando Gabi pide una Cuba libre, Elena se ríe y responde "hasta la victorria siempre" (50), y luego la besa.

Analicemos ahora con más detalle cómo se codifica en el texto este momento glorificado en el discurso romántico. "Me entró en la boca como le entraba a todo, como si fuera la dueña" (51), cuenta Gabi, reforzando una vez más lo mercantil de su relación amorosa y destacando sus vínculos con el poder, para inmediatamente después establecer una relación de equivalencia entre la lengua de Elena y el caballo de Troya, así como entre el alma y la vagina: "Me metió un caballo de Troya con parlantes de rave y a mí se me abrió hasta el alma, quiero decir que me hubiera entrado un piano en la concha esa madrugada veneciana" (51). Cuando se produjo el acto sexual que "[le] partió el corazón" (51), "acab[ó] como una rinoceronta pariendo" (51) en un jacuzzi, lo cual se podría leer, a su vez, como un guiño hacia la estética no heteronormativa que comúnmente asocia lo acuático al amor lésbico. Así empezaron "los meses de las postales", cuando "la regencia había pasado de la cabeza a la pelvis" (52) y "el resto de [Gabi] la seguía" (52).

La euforia principal acabó con una grieta que "habría de unir[las] para siempre y que para siempre [las] unió nomás” (53). Así, la narradora acude de nuevo al uso del oxímoron y la estética neobarroca para revelar que el amor entre las dos no logró superar todos los obstáculos, ni las contradicciones: "La grieta fue la inevitable la fatal la feroz devoradora: la parca que mata amor galana billetera y hunde góndola, abate helicóptero [...] Mi Elena, la dorada la firme la poderosa, la diosa recia de uñas cortas, mi yegua mi belleza, mi agua mi carne mi ternera, mi Elena mi amor mi vida mi aliento, [...] estaba enferma" (54). La enfermedad y la muerte de una de las amantes convierte la narración en una parodia de melodrama y pone en juego una emotividad hiperbolizada, propia de la telenovela latinoamericana. Dicha emotividad está evocada explícitamente en el texto mediante un comentario hecho por Elena acerca de la conducta afectiva de Gabi: “Cáncer», me dijo, «no se cura». Y yo que en asado había mutado muté en mujer de Lot [...] me desmoroné y mientras caía hice mierda medio pabellón argentino: ahí sí me desplomé, caí en picada, me rompí. Elena miró, quieta, callada hasta que terminé de caer y me dijo que me deje de joder con exuberancias de latina pelotuda" (54). La narradora aprovecha paródicamente las mismas prácticas discursivas -términos enfáticos, expresiones exageradas, estructuras paratácticas o unas inacabables parástasis- cuando subraya, deconstruyendo de paso los binomios propios de la lógica falologocéntrica, que su pareja jugó en su vida el papel de "[su] mujer [su] marido [su] toro [su] doncella, [su] hermana [su] amante" (54) y que nunca se recuperó del todo tras su muerte, ni logró enamorarse de otra persona.

Los últimos meses compartidos con Elena se configuran en el texto como un tiempo de máxima felicidad, compenetración y aprendizaje. Su pareja se lo enseña todo y, gracias a las instrucciones, los discursos y el amor que recibe, se transforma. El cinismo constituye, sin duda, una parte importante de este legado. Cuando las amantes crean la segunda parte de exposición de la que la narradora formaba parte en Venecia, Elena le enseña a Gabi que el poder siempre se funda sobre y se aprovecha del sacrificio del otro, siendo una suerte de reflejo oblicuo del martirio: 
quedó lista "Sacrificio" parte uno y le pusimos las manos a la otra. Si sobre la ventana de occidente agonizaba un pobre Cristo de holograma, armamos sobre el vidrio del oriente al bello, al deslumbrante, al magno Vaticano. [...] Al Cristo le seguían varios mártires, para esos el reflejo fue de mármol. Tuvo cada uno sus regias catedrales y ligaron los dos más importantes el montón de oro montado en carabelas y la sede central del gran Banco Ambrosiano. Seguía nuestra obra [...] con las fotos de los desaparecidos, [...] el ícono de Walsh con los anteojos, el pañuelo de las madres, la silueta, los pibes robados como cosas, la negrura de los campos de tortura. A ellos les pusimos de reflejo a mucho político en mandato, los que hicieron del filo de su ausencia marionetas, los que se colgaron sus fotos de buscados en el pecho cual medallas del campo de batalla, los que hicieron de los pobres torturados [...] un siniestro capital de propaganda. (57-59)

Gabi asume entonces la lección nietzscheana de Elena de que la crueldad como valor del fuerte es inherente a la afirmación de la vida ("a su juicio lo que lleva de Cristo al Vaticano, del martirio al poder [...], es la pura voluntad de vivir y hacerse fuerte", 60), de que el sometimiento de los débiles por parte de los fuertes es poco menos que un orden natural del mundo ("siempre [habrá] un grupo que mata o será muerto, que medrará del trabajo de los otros o será apenas la materia de obra ajena", 60); "evidencia" ante la cual solo queda rendirse. Y Gabi lo hace: "Yo no acuerdo ni acordé y no me importó" (60).

El proceso de aprendizaje y de compenetración entre las dos no termina allí. Elena revela cómo le gustaría acabar la obra de arte que están construyendo: "te voy a dar mi cara -prometió Elena-, me transplanto a la tuya, vivo en vos y vos vivís conmigo para siempre, estamos juntas tus ojos de grafito y mi piel con palidez de cielos grises" (59). Así, al donarle su rostro, decide convertirlas a las dos en una suerte de encarnación paródica del mito platónico: van a pertenecer la una a la otra de forma exclusiva y eterna. Esta confesión generó, a los ojos de Gabi, "una nueva intimidad, nueva en el mundo no en [su] vida" (60). Antes de fusionarse en un solo cuerpo, el mismo proyecto, la idea de lo que iba a pasar, provocó el surgimiento de una sensación de unión y fusión: "charlábamos las dos y éramos dos, pero ese inédito mezclarse de dos carnes superaba al sexo en la pasión, nos hizo casi una, nos deshizo los bordes personales, vivimos en fusión como en hervor el tiempo que le quedó a Elena de vida" (60). Así, la narradora se burla de la supuesta función transformadora y epistemológica del amor, tal y como fue concebida por ejemplo por Julia Kristeva. En Historias de amor la investigadora identifica el amor con el sentido de la vida y el significado del lenguaje: el amor proporciona un fundamento para la cohesión de subjetividades y significados fragmentarios, así como un vínculo entre la palabra y el afecto. Desde esta perspectiva, nuestras autobiografías cobran sentido mediante los relatos que construimos por y para el otro en el seno de una relación amorosa. Cuando estamos enamorados, el otro idealizado refleja nuestra propia imagen ideal, pero sigue siendo otro: el amor "reina entre las fronteras del narcisismo y de la idealización. Su majestad el Yo se proyecta y glorifica, o bien estalla en pedazos y se destruye, cuando se contempla en Otro idealizado: sublime, incomparable, tan digno (¿de mí?) como yo pueda ser indigna de él y, sin embargo, hecho para nuestra unión indestructible" (Kristeva 1987: 5-6).

Tras la muerte de Elena, la protagonista se comporta de una manera doblemente heterodoxa -desde la perspectiva de la cultura patriarcal, por un lado, y de la lésbica radical, 
por el otro- al crear una relación abierta con dos hombres: vive con Tadzio, el empleado italiano, y Hans, el exnovio alemán de Elena, en una suerte de simbiosis poliamorosa. Cuando Gabi se hunde en la tristeza, los muchachos "la animan con sus mimos": “Tadzio cocina pastas, Hans el postre y entre todos tomamos mucho vino y nos vamos a la cama los tres juntos y cogemos en tres lenguas diferentes. Yo en español, Tadzio italiano y Hans, claro, en alemán; nuestro erotismo parece un congreso de la ONU" (Cabezón Cámara 2014: 61). El autorrelato de la vida íntima de los tres amantes parodia así el ideal queer anti(hetero)normativo y las prácticas discursivas poliamorosas.

Como hemos podido observar, la novela parodia y desmitifica: el mito del amor romántico como fuerza altruista y alejada de la lógica del capitalismo, el mito de la "dominación masculina" como parte inherente de la vida en pareja (el mito de Cenicienta), el mito del primer beso, el mito del happy end, el mito del poliamor y, finalmente, el mito platónico de la "media naranja", introduciendo una distancia irónica con respecto a todas y cada una de las más poderosas narraciones románticas. Así, en Romance abundan citas paródicas que subrayan el carácter cultural del amor, demostrando que fueron los textos de distinta índole, procedentes tanto de la literatura clásica como de la cultura de masas, los que condicionaron el enamoramiento de Gabi.

\section{CONCLUSIONES O "NOTAS" SOBRE EL CINISMO}

¿Qué papel desempeña el autorretrato ficcional de Gabi, qué efectos tendrá sobre el espectáculo cínico de la sociedad actual, en el que, como observa la filósofa ética polaca Magdalena Środa, los hipócritas no tienen que fingir ser idealistas, pero los idealistas tienen que fingir ser hipócritas (1997: 37)?

Gabi, una supuesta tránsfuga de origen paria que, en el ámbito público, primero asume la pose de una activista social sacrificada, para después convertirse a los ojos de sus seguidores en una líder política comprometida y "la voz de los sin voz", sabe que participar, actuar, comprometerse con la causa de otros, significa transigir, allanarse, venderse al sistema. Su cinismo es lucidez: no se permite la falsa conciencia, no se deja engañar por la demagogia, el error o la mentira ideológica. Al mismo tiempo, sin embargo, no vacila en sacrificar su clarividencia a las necesidades (Sloterdijk 2007: 31, 43). Participa en los juegos del poder, adhiere amistosamente al capital, en fin, se adapta a las circunstancias en nombre de un melancólico "da igual, nada tiene sentido" o, para citarla a ella misma, "Yo no acuerdo ni acordé y no me importó" (Cabezón Cámara 2014: 60). $\mathrm{Su}$ "encogerse de hombros", que debemos entender como una aceptación perversa del estado de cosas, concluye en un "nihilismo pasivo" que Slavoj Žižek (2011b) identifica como una postura dominante entre las élites globales de la época del capitalismo tardío. El "nihilismo pasivo", que Gabi aprendió de Elena, se distingue, en términos del pensador esloveno, precisamente por el cinismo, pero también por la indiferencia, el relativismo moral y el hedonismo consumista, y está provocado por el "déficit motivacional". Esta postura desemboca en la novela, como hemos podido observar, en una voluntad política amputada y en la interiorización por parte de Gabi del "mito de un mundo postideológico" 
(Žižek 2011b). El orden social histórico y concreto le parece inalterable y eterno, mientras que el cambio del sistema se convierte en lo no-pensable, constituyéndose, en su autobiografía, como el límite de las creencias colectivas.

Ahora bien, ¿¿cuáles son las modalidades retóricas que traducen esta actitud de la protagonista? El cinismo de su "doble irónico", la narradora del relato autobiográfico que leemos, por un lado, se manifiesta en el uso del discurso paródico que se dirige contra los idealismos, los dogmatismos, los esencialismos. La suya es una voz socarrona y mordaz que se regodea con la concienciación sobre la realidad, una voz profanadora de todas las fes, desdeñosa de todos los valores, desenmascaradora de todas las ilusiones. Por otro lado, tal y como podríamos esperar de una verdadera autobiografía tránsfuga, Gabi, al contar su propia historia, se erige en portadora de memoria colectiva, en vocera de los silenciados, los excluidos. Y no solo porque salmodia, incansablemente, el comunitario, el militante "los míos", sino porque su voz se contagia de los tonos, del ritmo, del habla de "los suyos". Los momentos climáticos de su historia, los que refieren unas verdaderas experiencias límite para el lenguaje -los casi inefables estados del amor, la muerte o el dolor- se desarman y se rinden a la vitalidad del lenguaje coloquial. En forma coloquial se citan también los numerosos pasajes del evangelio, los mitos griegos o las referencias históricas. Más aun, en el hecho de que su prosa se convierta a ratos en versos, de preferencia octasílabos, también llamados de "arte menor", o sea en versos propios de la tradición romancera, deberíamos ver otro de los modos en que la autobiógrafa "minoriza" o "reterritorializa" su escritura, es decir, un modo en que socava los lenguajes modelo de la supremacía cultural: los dogmatismos de la religión oficial, los estereotipos de la moral conservadora, las consignas vacías de la jerga política (incluida la retórica de izquierda), los clichés de la cultura de masas.

Pero lo cierto es que Gabi-la narradora echa mano de todos los géneros y formas culturales que están a su alcance: desde los mitos religiosos hasta las telenovelas y los formatos massmediáticos (televisión, blog), desde la poesía conceptista hasta el romance o el subgénero de la cumbia villera. En fin, podemos decir lo que Segura Bonnett ha observado sobre la narración en La virgen de los sicarios de Fernando Vallejo: que la enunciación cínica de Gabi se vale de cualquier recurso, pero no para generar la convicción como los sofistas, sino para "generar la incredulidad" $(2004: 133)^{6}$. Y una reflexión que solo trasluce una radical desconfianza -incluso sobre sí misma- necesariamente castra toda posibilidad de alterar realmente el status quo.

Por supuesto, no pretendemos decir con esto que Cabezón Cámara ha escrito una novela cínica o nihilista, sino que ha construido en ella el autorretrato de una escritora que ya no puede simplemente ejercer una crítica desde su trinchera combatiente, como los antiguos quínicos la hacían a los discursos idealistas. Tampoco puede vendernos una "sanata, la cosa llorona, bolche, quejosa", como diría Lamborghini (1980: 49), o sea, un testimonio que "val[ga] por el sufrimiento" que presenta y "por las causas nobles de este sufrimiento" (49). Lo único que puede hacer hoy, cuando las ideologías han quedado

\footnotetext{
6 Por supuesto, a nivel de otra instancia enunciadora, la de la autora implícita que organiza el relato, toda esta prodigiosa mezcla de tonos, registros, géneros y formas culturales forma parte de la estrategia antirrepresentacional de la novela que, como subraya Martín Kohan, "desfigura la realidad social para contarla como exceso y en desborde" (2015: 12).
} 
desenmascaradas, es exhibir el cinismo compartido por todos y del cual ella misma es cómplice. En otras palabas, la narradora asume la máscara cínica para desenmascarar y desmontar los presupuestos del cinismo, un fenómeno social de enorme vitalidad, versatilidad y de un gran poder radial. Al mismo tiempo, sin embargo, mantiene una tensión y apunta a una todavía existente diferencia entre lo que serían las verdaderas convicciones políticas y morales, su profesión hipócrita y una burla socarrona de las mismas

(cf. Środa 1997: 38). Por ello, en el lenguaje de la narración -burlesco, juguetón- es posible reconocer, más que una aceptación resignada, una ironía combativa del orden establecido y reivindicadora de un mundo más libre, mejor.

\section{BIBLIOGRAFÍA}

Ahmed, Sara (2019) La promesa de la felicidad. Una crítica cultural al imperativo de la alegría. Buenos Aires, Caja Negra.

Anderson, Linda (2011) Autobiography. London, Routledge.

ARfuCH, Leonor (2002) El espacio biográfico. Dilemas de la subjetividad contemporánea. Buenos Aires, Fondo de Cultura Económica.

---- (2013) Memoria y autobiografía. Exploraciones en los límites. Buenos Aires, Fondo de Cultura Económica.

----- (2018) La vida narrada. Memoria, subjetividad y política. Villa María, Eduvim.

Bataille, George (2010) El erotismo. Barcelona, Tusquets Editores.

BeCK, Ulrich y BECK-GeRnsheIm, Elisabeth (2001) El normal caos del amor. Las nuevas formas de la relación amorosa. Barcelona - Buenos Aires - México, Paidós.

Bourdieu, Pierre (1988) La distinción. Criterio y bases sociales del gusto. Madrid, Taurus. ---- (2000) La dominación masculina. Barcelona, Anagrama.

ButLER, Judith (2002) Cuerpos que importan: sobre los límites materiales y discursivos del sexo. Buenos Aires, Paidós.

---- (2006) Vida precaria. El poder del duelo y la violencia. Buenos Aires, Paidós.

---- (2009) Dar cuenta de sí mismo. Violencia ética y responsabilidad. Buenos Aires, Amorrortu.

Cabezón Cámara, Gabriela (2014) Romance de la Negra Rubia. Buenos Aires, Eterna Cadencia.

Debord, Guy (2008) La sociedad del espectáculo. Buenos Aires, La Marca Editora.

Deleuze, Gilles (2006) La literatura y la vida. Ed. de Silvio Mattoni. Córdoba (Argentina), Alción Editora.

De Man, Paul (1991) Visión y ceguera. Ensayos sobre la retórica de la crítica contemporánea. Río Piedras, Editorial de la Universidad de Puerto Rico.

Domínguez, Nora (2017) "Formas de vida, destinos globales. Sobre Fernanda Trías, Lina Meruane y Gabriela Cabezón Cámara”. Revista Iberoamericana. LXXXIII (261): 823-835. (2018) "Entre lo singular y lo colectivo". CELEHIS. Revista del Centro de Letras Hispanoamericanas. 27 (36): 35-45. 
GIDDENs, Anthony (2004) La transformación de la intimidad: sexualidad, amor y erotismo en las sociedades. Madrid, Catédra.

Glucksmann, André (1982) Cinismo y pasión. Barcelona, Anagrama.

Goicoechea, María Eugenia (2018) "Una mirada al desarrollo urbano en la ciudad de Buenos Aires bajo la hipótesis de micro-segregación: explorando sus tendencias y alcances". En: Sonia Vidal Koppmann (comp.) Dinámica socio-espacial de regiones metropolitanas: claves para el análisis de un fenómeno complejo. Buenos Aires, IMHICIHU: 135-170.

Hutcheon, Linda (2000) A Theory of Parody: The Teachings of Twentieth-Century Art Forms. Urbana - Chicago, University of Illinois Press.

Illouz, Eva (2009) El consumo de la utopía romántica. El amor y las condiciones sociales del capitalismo. Buenos Aires - Madrid, Katz Editores.

KAPUściński, Ryszard (1996) Lapidarium II. Warszawa, Czytelnik.

Kohan, Martín (2014) El país de la guerra. Buenos Aires, Eterna Cadencia.

---- (2015) “Desfiguraciones”. Hispamérica: Revista de literatura. 44 (132): 3-16.

Kristeva, Julia (1987) Historias de amor. México, Siglo XXI Editores.

LAMBorghini, Osvaldo (1980) "El lugar del artista. Entrevista a Osvaldo Lamborghini". Lecturas críticas. I (1): 48-51.

---- (1988) Novelas y cuentos. Barcelona, Ediciones del Sebral.

Leibovici, Martine (2011) "Le «Verstehen» narratif du transfuge: Incursions chez Richard Wright, Albert Memmi et Assia Djebar". Tumultes. 36: 91-109.

LoRCA, Jorge (2014) “Estrategias cínicas como recurso estético”. Revista de teoría del arte. 25: 97-107.

Montes, Alicia (2018) "Genealogía del sacrificio: cuerpo y memoria en Romance de la Negra Rubia de Gabriela Cabezón Cámara”. Debate Feminista. 56: 26-42.

Pardo, María Laura (2008) "Un sistema de creencias discriminatorio". Página 12. 12.05.2008. https://www.paginal2.com.ar/diario/elpais/1-104017-2008-05-12.html [26.09.2020].

Ricceur, Paul (2001) “Acerca de la interpretación". En: Del texto a la acción: Ensayos de herméutica II. Buenos Aires, Fondo de Cultura Económica: 15-36.

Rincón, Omar (2006) "Estéticas de telenovelas". Cátedra de Artes. 2: 43-49.

RorTy, Richard (1991) Contingencia, ironía y solidaridad. Barcelona, Paidós.

RousseAu, Jean Jacques (s.f. [1751]) Discurso sobre la siguiente cuestión. ¿Cuál es la virtud más necesaria para los héroes?; ¿Quiénes son los héroes a los que falta esa virtud? https://www. lacavernadeplaton.com/articulosbis/textscavern/discursorousseaul314.pdf [20.09.2020].

Segura Bonnett, Camila (2004) "Kinismo y melodrama en La virgen de los sicarios $y$ Rosario Tijeras". Estudios de Literatura CoLombiana 14: 111-136.

Sloterdijk, Peter (2007) Crítica de la razón cínica. Madrid, Ediciones Siruela.

Szczurowski, Michał (2018) "Patos". En: Zbigniew Kadłubek, Beata Mytych-Forajter y Aleksander Nawarecki (eds.) Ilustrowany słownik terminów literackich. Historia, anegdota, etymologia. Gdańsk, słowo/obraz terytoria: 368-372.

ŚRODA, Magdalena (1997) "Cynizm jako widowisko". Etyka. 97: 25-39.

ŽIžEK, Slavoj (2011a) Primero como tragedia, después como farsa. Tres Cantos, Ediciones Akal.

----- (2011b) En defensa de causas perdidas. Madrid, Akal. 